\title{
К.Р. Юсиф-заде
}

Военный госпиталь Государственной пограничной службы Республики Азербайджан, Баку

Азербайджанский медицинский университет, Баку

\section{Минимизация доступов при лапароскопической холецистэктомии}

Цель исследования: оценить степень влияния числа эндоскопических доступов на эффективность лапароскопической холецистэктомии. Методы: для сравнительной оценки результатов хирургического лечения, осуществленного трех- и четырехпортовым лапароскопическим доступом, был проведен ретроспективный анализ историй болезни 118 пациентов. Было сформировано 2 группы пациентов: оперированные трехпортным лапароскопическим доступом $(n=60)$ и с помощью четырехпортного доступа $(n=58)$. Одним из важных этапов научных исследований была гистоморфологическая характеристика удаленного желчного пузыря, которую выполнили всем 118 больным, перенесиим миниинвазивные операции. Для субъективной оценки проявлений болевого синдрома использовали общепринятую визуально-аналоговую шкалу боли. Результаты: 60 больным проведена лапароскопическая холецистэктомия доступом из трех портов (основная группа), 58 больным из четырех портов (группа сравнения). В основной группе у 53 (88,3\%) пациентов отмечено отсутствие каких-либо болевых ощущений, и только 3 из них жаловались на наличие легкой и 4 - умеренной боли, соответственно, на 7-е сут после хирургического вмешательства. В группе сравнения данные показатели составили 50 (86,2\%), 2 и 6 человек, соответственно. Сроки госпитализации и нетрудоспособности были сравнительно меньшими при минимальном числе портов: 3,2 и 4,4 сут, соответственно. В основной группе длительность нетрудоспособности составила 8,5 против 10,6 сут в группе сравнения. Заключение: методика трехпортного лапароскопического доступа позволяет значительно сократить частоту клинических проявлений болевого синдрома, достичь максимального косметического эффекта, существенно уменьшить сроки послеоперационного реабилитационного периода, в результате чего наступает более ранняя активизация и восстановление трудоспособности больных.

Ключевые слова: лапароскопическая холецистэктомия, эндоскопический доступ, верификация, боль.

(Вестник РАМН. 2014; 9-10: 140-144)

\section{Обоснование}

Миниинвазивные технологии в практической медицине, особенно в абдоминальной хирургии, получили повсеместное и широкое распространение по причине наличия некоторых преимуществ перед традиционными оперативными вмешательствами, что обусловливается, прежде всего, простотой и доступностью выполнения технических приемов, значительным сокращением частоты развития осложнений, сроков госпитализации и реабилитационного периода, времени оперативного вмешательства, выраженным косметическим эффектом [1-3]. При этом по причине разработки и внедрения в хирургическую практику новых и более совершенных технических устройств продолжаются попытки по дальнейшей минимизации данной процедуры за счет уменьшения количества используемых троакаров [4-8]. В настоящее время возможности применения данных хирургических технологий все еще находятся в центре внимания зарубежных и отечественных ученых [9].

\section{K.R. Yusif-zade}

Military hospital of the Public Border Service of the Republic Azerbaijan, Baku Azerbaijan Medical University, Baku

\section{Minimization of Approach at Laparoscopic Cholecystectomy}

Objective: The aim of the study was to estimate the influence of the amount of endoscopic approaches on effectiveness of laparoscopic cholecystectomy. Methods: For the purpose of comparative evaluation of the results of surgical treatment of a three- and fourport laparoscopic approach was a retrospective analysis of case histories of 118 patients. Patients were divided into two groups: operated by using three laparoscopic approaches (60 patients) and unused optional fourth trocar (58 patients). One of the important stages of scientific research was histological morphology characteristic of the removed gallbladder, which was performed in 118 patients who underwent minimally invasive operations. For subjective assessment of the manifestations of pain syndrome used the conventional visual analog scale of pain (VAS). Results: 60 patients underwent threeport laparoscopic cholecystectomy (the main group) and 58 patients underwent four-port LC (group of comparison). In the main group 53 (88.3\%) patients showed absence of any pain, and only 3 from them complained of existence easy and 4 - moderate pain respectively for the $7^{\text {th }}$ day after surgical intervention. In group of comparison these indicators made: respectively $50(86.2 \%), 2$ and 6 people. Terms of hospitalization and disability were relatively lower at the minimum number of ports: respectively 3.2 and 4.4 days. In the main group duration of disability made 8.5 days against 10.6 days in group of comparison. Conclusion: Reducing the number of laparoscopic approach significantly reduced the frequency of clinical manifestations of pain, achieved maximum cosmetic effect, significantly shortens postoperative rehabilitation period, and comes earlier activation and rehabilitation of patients.

Key words: laparoscopic cholecystectomy, approach, verification, pain.

(Vestnik Rossiiskoi Akademii Meditsinskikh Nauk - Annals of the Russian Academy of Medical Sciences. 2014; 9-10: 140-144) 
Цель исследования состояла в оценке степени влияния числа эндоскопических доступов на эффективность лапароскопической холецистэктомии.

\section{Методы}

\section{План исследования}

Нерандомизированное контролируемое исследование.

\section{Критерии соответствия}

В исследование были включены 118 больных, госпитализированных по поводу желчнокаменной болезни и подвергшихся хирургическому лечению.

\section{Условия проведения}

Исследование проведено в Военном госпитале Государственной пограничной службы Азербайджанской Республики

\section{Продолжительность исследования}

Исследование проводилось в период с февраля 2011 по апрель 2013 г.

\section{Описание медициского вмешательства}

Перед операцией каждый больной проходил соответствующий комплекс обследований, включающий общее физикальное, лабораторное исследование, УЗИ органов брюшной полости, КТ, ЭКГ, рентгенографию органов грудной клетки; при необходимости более углубленного обследования состояния желчных протоков - МРТ, эндоскопическую ретроградную холангиопанкреатографию.

Техника введения трех троакаров: сразу над пупком через пятимиллиметровый разрез вводится первый пятимиллиметровый троакар. После осмотра брюшной полости в условиях карбоперитонеума (12-14 мм рт.ст.) на уровне шейки пузыря гипотетически на коже проводится линия, которая приходится приблизительно на 5 см ниже мечевидного отростка грудной кости. На 1 см справа от этой срединной линии параллельно реберной дуге проводится разрез протяженностью 10-12 мм. Десятимиллиметровый троакар вводится в брюшную полость таким образом, чтобы круглая связка печени располагалась слева от места вхождения в брюшную полость. Третий троакар (5 мм) кожным надрезом вводится приблизительно под проекцией дна пузыря, на 1-2 см ниже угла реберной дуги. При необходимости введения 4-го пятимиллиметрового троакара его вводят на уровне между продольной линией переднеподмышечной и средней ключичной, и по поперечной линии он приходится на уровне или ниже пупка (рис. 1 и 2).

\section{Методы исследования}

Для субъективной оценки проявлений болевого синдрома использовали общепринятую визуально-аналоговую шкалу боли (ВАШ) [10]. Пациент в ходе наблюдений отмечал степень болевых ощущений точкой на прямой линии длиной $10 \mathrm{~cm}$. Начальная точка прямой обозначала полное отсутствие боли (0), далее следуют отметки, характеризующие слабую, умеренную и сильную боль, а максимальное значение, свидетельствующее о наличии невыносимой, по мнению больного, боли составляло 10 (рис. 3).

\section{Статистический анализ}

Принцип расчета размера выборки

Размер выборки предварительно не рассчитывался.

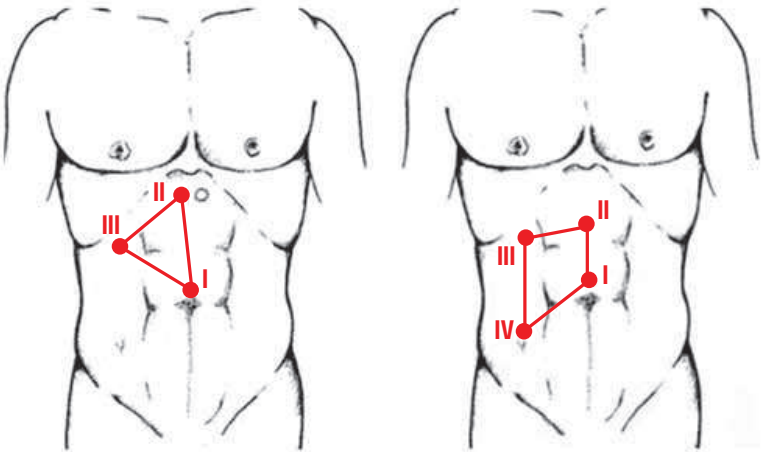

Рис. 1. Расположение троакаров (схематическое изображение). Примечание. а) три троакара; б) четыре троакара.

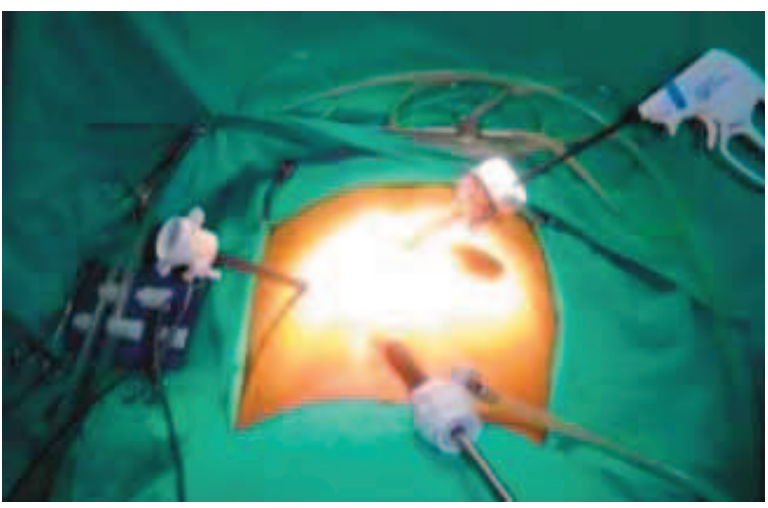

Рис. 2. Лапароскопическая холецистэктомия с тремя троакарами.

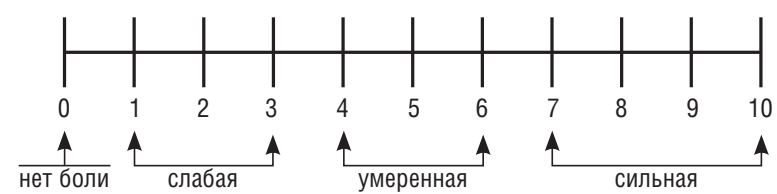

Рис. 3. Визуальная аналоговая шкала интенсивности болевого синдрома.

\section{Методы статистического анализа}

Статистическая обработка полученных данных проводилась на персональном компьютере с использованием редактора электронных таблиц Microsoft Excel 2007 и пакета прикладных программ STATISTICA v. 7.0 (StatSoft Inc., США). Результаты исследования обработаны методами вариационной статистики. Для характеристики группы однородных единиц были определены их средние арифметические величины (M) и стандартные ошибки (m). При изучении качественных признаков были определены абсолютные численности групп, их доли, выраженные в процентах; для характеристики частоты качественного признака - его средняя ошибка. В целях статистической обработки данных применен параметрический t-критерий Стьюдента. Поскольку для обследуемых групп условие нормальности распределения не выполнялось, для статистической обработки данных ВАШ между двумя группами был использован непараметрический $U$-тест Манна-Уитни. Различия считали статистически значимыми при $p<0,05$. 


\section{Результаты}

\section{Участники исследования}

Для сравнительной оценки результатов хирургического вмешательства, осуществленного трех- и четырехпортным лапароскопическим доступом, был проведен ретроспективный анализ историй болезни 118 больных (25; $21,2 \%$ - мужчин, 93; 78,8\% - женщин), обратившихся в клинику в период с февраля 2011 по апрель 2013 г., которым было выполнено 118 лапароскопических холецистэктомий. Сформировали 2 группы больных: основную, в которую вошли 60 пациентов, которым была проведена лапароскопическая холецистэктомия доступом из трех портов, и группу сравнения - 58 человек, которым холецистэктомия была выполнена доступом из 4 портов. Из общего числа пациентов $(n=118)$ острый воспалительный процесс имел место у 12 человек, хронический - у 101, у 5 пациентов диагностировали полипоз желчного пузыря.

У $10(8,5 \%)$ человек желчнокаменная болезнь была осложнена холедохолитиазом. У 3 (2,54\%) пациентов диагностировали гангренозный холецистит, у 9 (7,6\%)флегмонозный холецистит, у $77(65,3 \%)-$ хронический холецистит, у 24 (20,33\%) - обострение хронического холецистита, у 5 (4,23\%) - полипоз желчного пузыря (табл. 1). Возраст больных варьировал от 29 до 75 лет (табл. 2). Средняя продолжительность пребывания пациента в стационаре составила 3,0 койко-дня. У 99 (83,9\%) пациентов толщина стенки желчного пузыря была равна 2-4 мм, у $16(13,6 \%)-4-8$ мм, у $3(2,5 \%)$ - больше 8 мм. У $54(45,8 \%)$ больных размер камня в желчном пузыре был

Таблица 1. Результаты гистологического исследования желчных пузырей у обследуемых

\begin{tabular}{|l|c|c|}
\hline \multicolumn{1}{|c|}{ Формы холецистита } & \multicolumn{2}{c|}{ Число исследований } \\
\cline { 2 - 3 } & Абс. & $\%$ \\
\hline Гангренозный & 3 & 2,54 \\
\hline Флегмонозный & 9 & 7,63 \\
\hline Хронический & 77 & 65,3 \\
\hline Обострение хронического холецистита & 24 & 20,3 \\
\hline Полипоз желчного пузыря & 5 & 4,23 \\
\hline Всего & 118 & 100 \\
\hline
\end{tabular}

Таблица 2. Распределение больных по возрасту

\begin{tabular}{|l|c|c|}
\hline \multicolumn{1}{|c|}{ Возрастные группы } & \multicolumn{2}{c|}{ Число больных } \\
\cline { 2 - 3 } & Абс. & $\%$ \\
\hline Младше 35 лет & 28 & 23,7 \\
\hline 35-45лет & 31 & 26,3 \\
\hline 46-50 лет & 15 & 12,7 \\
\hline 51-60 лет & 21 & 17,8 \\
\hline Старше 60 лет & 23 & 19,5 \\
\hline Всего & 118 & 100 \\
\hline
\end{tabular}

Таблица 3. Показатели визуальной аналоговой шкалы при лапароскопической холецистэктомии

\begin{tabular}{|l|c|c|}
\hline Срок, сут & Основная группа $(\boldsymbol{n}=\mathbf{6 0})$ & Группа сравнения $(\boldsymbol{n}=\mathbf{5 8})$ \\
\hline $1-\mathrm{e}$ & $3,90 \pm 0,11$ & $4,10 \pm 0,10$ \\
\hline $3-и$ & $1,85 \pm 0,12$ & $2,40 \pm 0,12 *$ \\
\hline $7-\mathrm{e}$ & - & $0,10 \pm 0,04$ \\
\hline
\end{tabular}

Примечание. * - различие показателя относительно основной группы статистически значимо $(p<0,010)$. менее 10,0 мм,у $28(23,7 \%)-10,0-15,0$ мм, у $16(13,6 \%)-$ $15,0-20,0$ мм, у $20(16,9 \%)$ - больше 20,0 мм.

При верификации полученных данных гистоморфологические исследования препаратов удаленного желчного пузыря в основном подтвердили результаты ультразвуковой диагностики [11].

\section{Основные результаты исследования}

Показатели визуальной аналоговой шкалы при лапароскопической холецистэктомии представлены в табл. 3.

Результаты, полученные при морфологическом исследовании желчных пузырей, удаленных методом лапароскопической холецистэктомии, свидетельствуют о наиболее частом развитии у обследованных пациентов хронического холецистита (у 101; 85,6\%), который характеризовался определенными морфологическими признаками: атрофией слизистой оболочки желчного пузыря, слабой или умеренной лимфоцитарно-плазмоцитарной инфильтрацией. Как правило, наблюдался очаговый склероз в подслизистом, а иногда и в мышечном слое. В случаях развития хронического холецистита встречались метапластические изменения в эпителии (рис. 4). Метаплазия антрального типа имела место в 9,63\% случаях. Наряду с этим только в 4 случаях $(0,98 \%)$ выявлялась интестинальная, в 2 случаях $(0,49 \%)$ - эндокринно-клеточная, а в 1 случае $(0,24 \%)-$ плоскоклеточная метаплазия.

В 85,6\% (101 из 118) случаев развития хронического холецистита наблюдали синусы Рокитанского-Ашоффа, покрытые эпителиальными клетками, простирающимися от слизистой оболочки до более глубоких слоев стенки желчного пузыря. Морфологические признаки других патологических состояний (в частности, полипоза) в материалах удаленных желчных пузырей встречались сравнительно редко - у $5(4,2 \%)$ больных. Макроскопически полипы располагались в теле желчного пузыря и в области его дна. По результатам микроскопических исследований основу полипов составляли многочисленные пенистые макрофаги - ксантомные клетки. Эти клетки, имеющие в цитоплазме много холестерина, при окрашивании гематоксилином и эозином имели четко различающиеся клеточные мембраны и ядра (рис. 5).

Поверхность полипов, как и в слизистой оболочке нормального желчного пузыря, покрыта однослойными кубическими и цилиндрическими эпителиальными клетками. Во всех случаях слизистая оболочка была бархатистой. Средняя толщина стенки желчного пузыря составила $1,88 \pm 0,33$ мм. Ни в одном случае с полипами в эпителии не определялись дис- и метаплазия.

Сравнительный анализ эффективности выполненных оперативных вмешательств и оценку результатов лечения больных исследуемых групп осуществляли с учетом времени оперативного вмешательства, течения послеоперационного периода, сроков госпитализации, косметического результата и степени выраженности послеоперационного болевого синдрома.

Длительность оперативного вмешательства значительно не различалась и зависела от вариантов анатомии, степени воспалительного процесса в гепатикопанкреатодуоденальной зоне и времени, потраченного на гемостаз. Среднее операционное время для процедуры лапароскопической холецистэктомии с тремя портами составило $30,6 \pm 0,04$ против $35,2 \pm 0,10$ мин для лапароскопической холецистэктомии с четырьмя портами (время операции было записано от начала пункции иглой Вереса до извлечения последнего троакара из раны). 


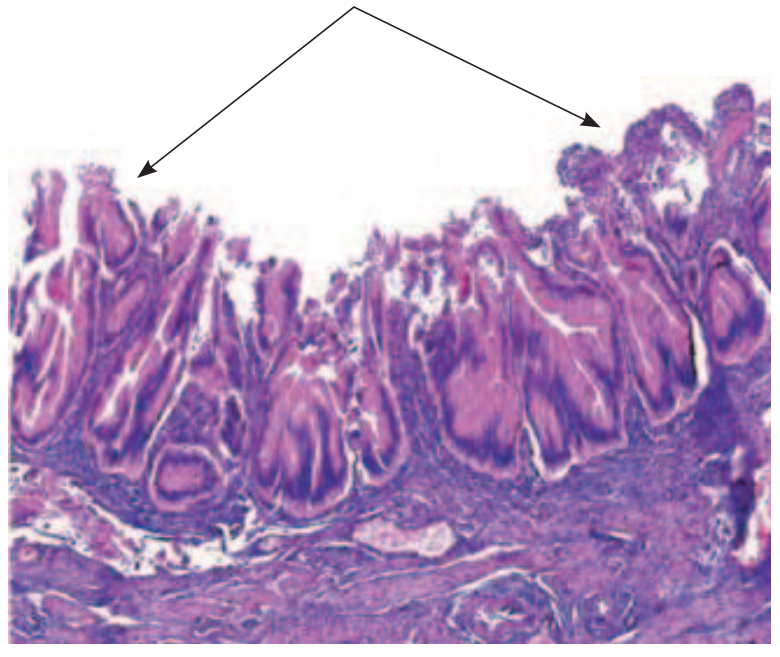

Рис. 4. Метаплазия антрального типа в слизистой оболочке желчного пузыря (участок слизистой оболочки между двумя стрелками). Окраска гематоксилином и эозином. Ув. $\times 100$.

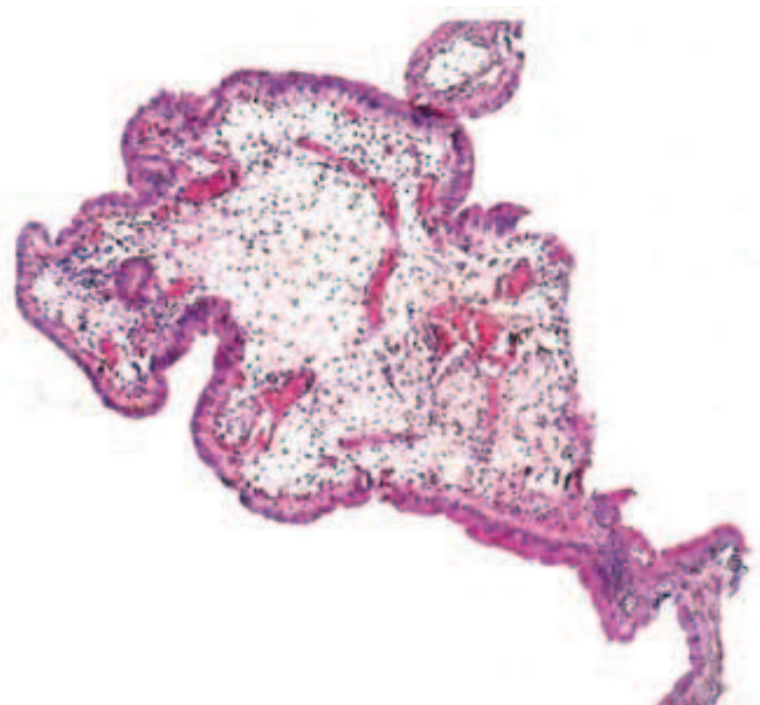

Рис. 5. Холестериновый полип. Окраска гематоксилином и эозином. Ув. $\times 40$.

Примечание. Наружный слой полипа покрыт однослойным эпителием, а основу заполняют многочисленные пенистые макрофаги.

Таблица 4. Сравнительная эффективность различных методик лапароскопической холецистэктомии

\begin{tabular}{|l|c|c|}
\hline \multicolumn{1}{|c|}{ Параметры оценки } & Основная группа $(\boldsymbol{n = 6 0})$ & Группа сравнения $(\boldsymbol{n}=\mathbf{5 8})$ \\
\hline Продолжительность госпитализации, сут & $3,2 \pm 0,10$ & $4,4 \pm 0,16^{*}$ \\
\hline Длительность нетрудоспособности, сут & $8,5 \pm 0,06$ & $10,6 \pm 0,14^{*}$ \\
\hline
\end{tabular}

Примечание. ${ }^{*}$ - различие показателя относительно основной группы статистически значимо $(p<0,001)$.

Таблица 5. Характер болевых ошущений в разных группах обследуемых

\begin{tabular}{|l|c|c|c|c|}
\hline \multirow{2}{*}{\multicolumn{1}{|c|}{ Болевой симптом }} & \multicolumn{2}{|c|}{ Основная группа $(\boldsymbol{n = 6 0 )}$} & \multicolumn{2}{c|}{ Группа сравнения $(\boldsymbol{n}=\mathbf{5 8})$} \\
\cline { 2 - 5 } & Абс. & Абс. & 50 & \\
\hline Отсутствие боли & 53 & 88,3 & 2 & 3,4 \\
\hline Легкая боль & 3 & 5,0 & 6 & 10,3 \\
\hline Умеренная боль & 4 & 6,7 & 6 \\
\hline
\end{tabular}

На 1-е сут после оперативного вмешательства в обеих группах больных имел место выраженный послеоперационный болевой синдром. На 3-и сут наблюдали значительное купирование болевых ощущений, причем данная тенденция чаще выявлялась в основной группе больных, оперированных трехтроакарным доступом (см. табл. 3).

Для послеоперационного контроля болевого синдрома внутримышечная инъекция Трамала (100 мг) и Кетонала (100 мг) проводилась каждые 6 и 8 ч, соответственно, в течение первых 24 ч после операции. У больных группы сравнения прием анальгетиков превысил по продолжительности таковой в основной группе приблизительно на 1 сут.

Сроки госпитализации и нетрудоспособности были сравнительно меньшими при минимальном числе портов (табл. 4). Время пребывания в стационаре пациентов, оперированных с тремя портами, по сравнению с традиционным четырехпортным способом было меньше и составило 3,2 и 4,4 сут, соответственно.

У 53 пациентов основной группы отмечено отсутствие каких-либо болевых ощущений, и только $3(5,0 \%)$ и $4(6,7 \%)$ из них жаловались на наличие легкой и умеренной степени болевого симптома, соответственно, на 7-е сут после хирургического вмешательства (табл. 5). Полное отсутствие признаков болевого синдрома в группе пациентов, у которых для удаления желчного пузыря применялся дополнительный четвертый троакар, зарегистрировано в 50 (86,2\%) случаях; $2(3,4 \%)$ и $6(10,3 \%)$ человек отметили наличие легкой и умеренной боли, соответственно (см. табл. 5).

\section{Нежелательные явления}

Какие-либо нежелательные явления не зарегистрированы.

\section{Обсуждение}

В эпоху лапароскопической хирургии уменьшение степени выраженности послеоперационного болевого синдрома и скорейшее восстановление пациентов - основная цель врача. Исследования по сравнению лапароскопической холецистэктомии с тремя и четырьмя троакарами показали отсутствие значительной разницы во времени операции, показателях успешности, требовании обезболивания и послеоперационном пребывании пациентов в больнице [8, 12], хотя некоторые хирурги выражают опасения по поводу безопасности уменьшения 
числа портов, утверждая, что это может привести к увеличению числа повреждений желчных протоков и других осложнений [13, 14]. Наше исследование не показало, что сокращенное число портов приводит к увеличению числа осложнений. Ни в одном случае из группы лапароскопической холецистэктомии с тремя портами для завершения процедуры дополнительный четвертый порт не понадобился.

Никаких повреждений общего желчного протока или случаев смерти в обеих группах не наблюдали. Выбор числа портов зависит от тщательного предоперационного обследования, анамнестических и лабораторных данных, степени выраженности воспаления желчного пузыря, уровня спаечного процесса в подпеченочном пространстве, возраста больного. Большинство пациентов в обеих группах выразили удовлетворение результатами хирургического вмешательства и эстетическим результатом после него. Косметический эффект был значительно лучше в группе больных, подвергшихся лапароскопической холецистэктомии с тремя портами.

В некоторых исследованиях показано, что уменьшение степени выраженности послеоперационной боли было непосредственно связано либо с сокращением размера, либо числа портов $[15,16]$. S. Trichac в своем исследовании указывает на безопасность и пре- с тремя портами с точки зрения приема анальгетиков, но он не подтверждает сокращение послеоперационного пребывания в больнице [8]. По результатам нашего исследования, пациентам, подвергшимся процедуре с тремя портами, потребовалось меньше анальгетиков, чем тем, кому использовали четыре порта. Подобные результаты продемонстрировали ученые из Ирландии, Непала и других стран $[15,16]$.

\section{Заключение}

Методика трехпортного лапароскопического доступа позволяет значительно сократить частоту клинических проявлений болевого синдрома, достичь максимального косметического эффекта, значительно сократить сроки послеоперационного реабилитационного периода, в результате чего наступает более ранняя активизация и восстановление трудоспособности больных.

\section{Конфликт интересов}

Авторы данной статьи подтвердили отсутствие финансовой поддержки / конфликта интересов, о которых необходимо сообщить.

\section{ЛИТЕРАТУРА}

1. Kwon A.H., Matsui Y. Laparoscopic cholecystectomy in patients aged 80 year and over. World J. Surg. 2006; 30: 1204-1210.

2. Litwin D.E., Cahan M.A. Laparoscopic cholecystectomy. Surg. Clin. North Am. 2008; 88 (6): 1295-1313.

3. Livingston E.H., Rege R.V. A nationwide study of conversion from laparoscopic to open cholecystectomy. Am. J. Surg. 2004; 188: 205-211.

4. Старков Ю.Г., Фёдоров А.В., Шишин К.В. Минимизация доступа в минимально инвазивной хирургии - тенденция или необходимость. Эндоскопическая хирургия. 2010; 2: 125126.

5. Шевела А.И., Анищенко В.В., Гмыза С.В. Идеальный доступ для холецистэктомии: NOTES, SILS или все-таки классическая лапароскопия? Эндоскопическая хирургия. 2012; 1: $15-19$.

6. Шумкина Л.В., Старков Ю.Г. Хирургия единого лапароскопического доступа: современные тенденции в лечении холецистита. Эндоскопическая хирургия. 2014; 1: 58-62.

7. Poon C.M., Chan K.W., Lee D.W., Chan K.C., Ko C.W., Cheung H.Y. et al. Two-port versus four-port laparoscopic cholecystectomy. Surg. Endosc. 2003; 17 (10): 16241627.

8. Trichak S. Three-port vs standard four-port laparoscopic cholecystectomy. Surg. Endosc. 2003; 17 (9): 1434-1436.
9. Sun H., Tang H., Jiang S., Zeng Li., Chen E.Q., Zhou Y., Wang Y.J. Gender and metabolic differences of gallstone diseases. World J. Gastroenterol. 2009; 15 (15): 1886-1891.

10. Huskisson E.C. Measurement of pain. Lancet. 1974; 2 (7889): 1127-1131.

11. Никитина М.Н., Пиманов С.И., Луд Н.Г. Ультразвуковая диагностика полипов желчного пузыря. Инструкция по применению. Витебск. 2008. 17 с.

12. Sun S., Yang K., Gao M., He X., Tian J., Ma B. Three-port versus four-port laparoscopic cholecystectomy: meta-analysis of randomized clinical trials. World J. Surg. 2009; 33: 1904-1908.

13. Kurpiewski W., Pesta W., Kowalczyk M., Głowacki L., Juśkiewicz W., Szynkarczuk R. et al. The outcomes of SILS cholecystectomy in comparison with classic four-trocar laparoscopic cholecystectomy. Videosurgery Miniinv. 2012; 7: 286-293.

14. Gurusamy K.S., Samraj K., Ramamoorthy R., Farouk M., Fusai G., Davidson B.R. Miniport versus standard ports for laparoscopic cholecystectomy. Cochrane Database Syst. Rev. 2010; CD006804.

15. Tuveri M., Tuveri A. Laparoscopic cholecystectomy: Complications and conversions with the 3-trocar technique: 10-year review. JSLS. 2007; 17: 380-384.

16. Hashimoto D., Hirota M., Yagi Y., Baba H. Umbilicus saving three-port laparoscopic cholecystectomy. WebMedCentral: Laparoscopy. 2011; 2: WMC001882.

\section{КОНТАКТНАЯ ИНФОРМАЦИЯ}

Юсиф-заде Кянан Рафаэль оглы, кандидат медицинских наук, начальник Военного госпиталя Государственной пограничной службы Республики Азербайджан, преподаватель кафедры хирургических болезней Азербайджанского медицинского университета

Адрес: Az1072, Баку, ул. Ф. Хойского, д. 99, тел.: +99 (450) 203-99-38, e-mail: yusifzadekr@yahoo.com 